\title{
Classification of Ph-Negative Chronic Myeloproliferative Disorders - Morphology as the Yardstick of Classification
}

\author{
Hans Michael Kvasnicka Jürgen Thiele \\ Institute of Pathology, University of Cologne, Cologne, Germany
}

\begin{abstract}
Key Words
Bone marrow histology $\cdot$ Chronic myeloproliferative disorders $\cdot$ Polycythemia vera $\cdot$ Chronic idiopathic myelofibrosis $\cdot$ Essential thrombocythemia
\end{abstract}

\begin{abstract}
Objective: Histopathology of bone marrow (BM) biopsies plays a crucial role in the interdisciplinary approach to diagnosis and classification of Ph-negative chronic myeloproliferative disorders. Based on careful clinicopathologic studies, BM features are critical determinants that help to predict overall prognosis, to detect complications such as progression to myelofibrosis and blast crisis, and to assess therapyrelated changes. Methods and Results: A systematic evaluation of BM histopathology allows an objective identification of cases of (true) essential thrombocythemia and their separation from early prefibrotic stages of chronic idiopathic myelofibrosis. By follow-up examinations that include BM biopsies, the progression of the disease process is unveiled, which is especially important for patients with initial polycythemia vera and prefibrotic chronic idiopathic myelofibrosis that may require a different therapeutic approach than the fullblown stages. Conclusion: BM biopsy should be considered as major diagnostic tool for evaluation and follow-up of patients enrolled in prospective studies.
\end{abstract}

Copyright $\odot 2007$ S. Karger AG, Basel
(C) 2007 S. Karger AG, Basel

1015-2008/07/0742-0063\$23.50/0

Fax +41 613061234

E-Mail karger@karger.ch

www.karger.com
Accessible online at:

www.karger.com/pat

\section{Introduction}

In the Philadelphia chromosome-negative chronic myeloproliferative disorders (CMPDs), examination of bone marrow (BM) biopsy specimens is essential to achieve a correct diagnosis and classification, as well as to monitor progression of the disease over time. In addition, histopathology permits a ready assessment of therapeutic effica$\mathrm{cy}$, assists in risk stratification of patients, and is predictive of prognosis. For this reason, a multidisciplinary approach is required by considering equally clinical and morphological data [1]. Regarding the major subtypes polycythemia vera (PV), essential thrombocythemia (ET), and chronic idiopathic myelofibrosis (CIMF) and allied disorders, ET is the most difficult entity to define. This adverse situation is reflected by the diversity of proposed diagnostic criteria. In particular, the diagnostic guidelines of the Polycythemia Vera Study Group (PVSG) [2-5] that are applied as gold standard in the majority of relevant clinical studies involving ET [6-10], have to be revised critically, since diagnosis of ET is usually performed by exclusion. On the other hand, a strikingly obvious heterogeneity of clinical and prognostic data was published $[11,12]$. In this context, the recently described JAK2 (V617F) mutation [13] that may be found in all CMPD subtypes [13-20] does not discriminate a certain entity of CMPDs when applying conventional clinical as well as morphological diagnostic guidelines including follow-up examinations. 


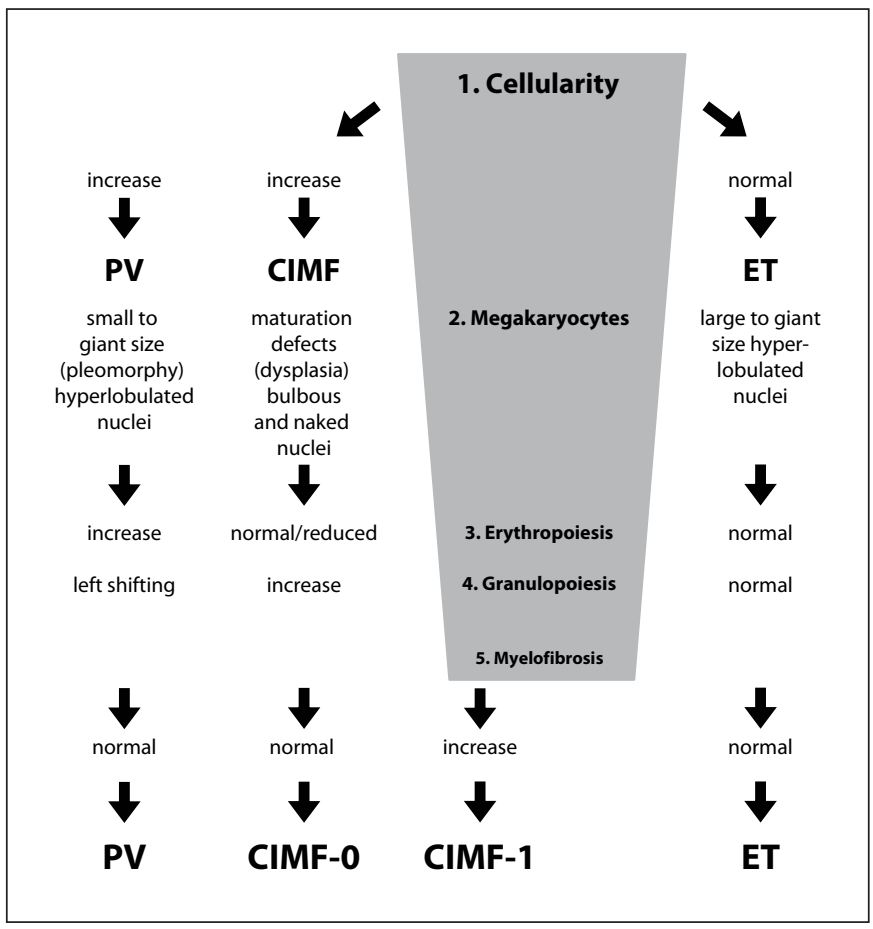

Fig. 1. Incidence of specific morphological features at time of diagnosis in various subtypes of CMPDs. ET = Essential thrombocythemia; $\mathrm{PV}=$ polycythemia vera CIMF = chronic idiopathic myelofibrosis.

It has been discussed that JAK2 (V617F) makes the mutated hematopoietic progenitor cells hypersensitive for a number of cy tokines and thereby leading to a growth advantage above the normal cell lineages in the BM [21, 22]. JAK 2 mutatus status is significantly correlated with the presence of the so-called PRV1 gene and the ability of endogenous erythroid colony formation or erythropoietin hypersensitivity and therefore a nearly $100 \%$ diagnostic specificity including homozygosity for the mutant allele was found for PV [23]. However, it was shown that a fraction of cases with ET and CIMF diagnosed according to the criteria of the PVSG [3-5] also exhibit this marker $[14-17,20,24,25]$. Altogether, detection of a JAK2 mutation facilitates the diagnosis of a CMPD and in particular the differentiation from reactive conditions, especially in very early stages of the disease process lacking the classical clinical and hematological characteristics [23]. Furthermore, it is noteworthy that progression of myelofibrosis in CMPDs is not influenced by the JAK2 mutation status, but is significantly associated with a relevant set of matrix modeling genes assumed to mediate fibrillogenesis [26].
The diagnostic impact of BM histopathology was recognized by the WHO classification [27] and for the first time positive criteria for ET were emphasized [28, 29]. The need of a more accurate ET diagnosis is obvious, in particular regarding therapeutic strategies and outcome, i.e. progression into myelofibrosis and blastic crisis [2931]. Thus, a scrutinized discrimination of initial CMPDs resulting in a clear-cut diagnosis of true versus false ET is warranted by a professional evaluation of BM biopsies in ongoing and prospective clinical trials [28, 29, 32].

\section{Definition and Standardization of Histopathological Features}

In accordance with the issues of the WHO classification [27], the different subtypes of CMPDs are characterized by specific histological patterns that are composed of distinctive features $[29,31,33,34]$ and are usually present at diagnosis (fig. 1). Although in quite a number of former studies these alterations have been elaborated [33], a conflict of opinion still exists whether an untrained pathologist would be able to recognize these features on hematoxylin-eosin (HE) stained BM sections [24]. Contrasting the determination of age-dependent cellularity and semiquantitative grading of myelofibrosis $[35,36]$, especially features of megakaryopoiesis may cause significant difficulties concerning definition and consequently recognition among different observers [37]. In this context a systematic evaluation including the arrangement of the megakaryocytes within the marrow space, i.e. histotopography and certain nuclear abnormalities in addition to maturation defects are crucial [35]. In the normal BM, megakaryocytes show a central distribution of single isolated cells [34]. In CMPDs, the increase in megakaryocytes is often associated with the formation of small clusters (at least three cells) to extensive groups (more than five cells). These megakaryocyte clusters may display either a loose or dense arrangement of cells [31, 33, 35]. Moreover, an abnormal dislocation of megakaryocytes towards the endosteal (paratrabecular) border is a highly conspicuous finding that is usually not found in reactive thrombocytosis [38]. Other features indicating a neoplastic process are peculiar nuclear aberrations and maturation defects that imply disturbances of the normal development of megakaryopoiesis [28, 29, 35]. These include an atypical nuclear hypolobulation that is often described as cloud-like leading to bulbous (plump, compact) nuclei [29] and anomalies of the chromatin pattern (mostly hyperchromasia) [28, 29, 35]. Fur- 
thermore, maturation defects include a remarkable deviation of the nuclear-cytoplasmic ratio with appearance of bizarre megakaryocytes [35]. It is noteworthy that all these changes may be detectable in megakaryocytes of different sizes (small, medium, large, giant) or ploidy status. Finally, so-called naked (denuded, bare) nuclei with condensed chromatin pattern may frequently be shown implicating an enforced cell turnover due to increased thrombocytogenesis. Of the other parameters, increase and left-shifting of neutrophil granulopoiesis or erythropoiesis may be a prominent feature [35] as well as reduction in the amount of nucleated red cell precursors depending on disease entity (fig. 1).

\section{Polycythemia Vera}

Unfortunately, the contribution of histopathology of the BM to the diagnosis of PV and to monitoring its progression has not been adequately appreciated $[37,39,40]$. In the original and updated criteria of the PVSG, BM findings are not even mentioned [5], and in the WHO classification, they are considered only as a minor criterion in substantiating the diagnosis [41]. Indeed, the major reason why $\mathrm{BM}$ morphology has been neglected as a useful tool in the diagnosis of PV is that the disease has been traditionally defined by clinical, laboratory and biologic parameters, which often do suffice to establish the diagnosis [39, 42]. However, when correlated with the clinical findings, a clear pattern of histopathologic features emerge that can be used to confirm the diagnosis in cases with borderline clinical data [40, 43]. For example, in very early stages of the dynamic disease process, a number of patients do not fulfill all of the established clinical and laboratory diagnostic criteria, particularly in regard to the red cell mass or hemoglobin/hematocrit values [5]. These cases have often been described as latent PV or benign erythrocytosis, and are generally regarded as a heterogeneous group that may eventually evolve into full-blown PV [37, 40, 43]. Importantly, some patients may have an initial/early prodromal phase of PV that is accentuated by thromboembolic episodes as first manifestation of disease [42], but in whom a diagnosis is not possible by conventional criteria. In these instances, demonstration of the characteristic histologic features of PV could lead to early diagnosis and appropriate therapy [37]. The BM biopsy performed at diagnosis also is important to establish a baseline against which subsequent specimens can be compared, because histopathology provides the best means to detect various phases of PV, particularly the terminal stages, so-called spent phase or post-polycythemic myeloid metaplasia (PPMM) and blast crisis $[28,29,34,40]$.

The histopathology of initial-early and full-blown PV is characterized by a hypercellular BM with trilineage proliferation (panmyelosis) of variable numbers of erythroid and granulocytic precursors, and with megakaryocytic increase that has distinctive morphologic features [37, 40,43]. Some of these findings have more significance than others in establishing the diagnosis of PV and distinguishing it from reactive or secondary polycythemia (SP) as well as from the other CMPDs. For example, although hypercellularity in relation to agematched hematopoiesis is a common feature of PV, it may occasionally also be encountered in cases of SP [37, 43] that usually present with a mildly to moderately increased hematopoiesis [37, 40, 43]. For easy recognition and quantification of neutrophil granulopoiesis versus erythropoiesis, a special stain like naphthol-A-SD-chloroacetate esterase or myeloperoxidase may be superior to the routine HE stain [32]. Following this staining procedure, it is apparent that in PV the normally small and rounded islets of nucleated erythroid precursors show a conspicuous enlargement and a tendency to merge into sheets [37, $40,43]$. Although these changes are significantly more pronounced in PV, they may be also expressed in a few cases with severe SP and therefore, this is not an entirely reliable diagnostic parameter [37]. A similar situation may be observed regarding the neutrophil cell lineage, because an increase in pro- and metamyelocytes (leftshifting) is frequently displayed in PV as well as SP [37, 43]. On the other hand, the features of the megakaryocytic proliferation in PV are characteristic and have been acknowledged to enable a distinction between PV, the other subtypes of CMPDs, and SP [40]. Previous studies reported by the PVSG showed that $95 \%$ of biopsies from patients with PV have an increase in the number of megakaryocytes [44], but others have observed that aside from the increase in numbers, the cytological appearance of this cell lineage exerts a discriminating impact [45]. It has been repeatedly emphasized that megakaryopoiesis in early as well as in full-blown PV displays a pleomorphous aspect, i.e., small or medium-sized, large and giant megakaryocytes are either dispersed or loosely clustered [37]. In particular, the mature megakaryocytes that have hyperlobulated nuclei but that fail to show other gross nuclear abnormalities, such as deviation from nuclear-cytoplasmic maturation may serve as diagnostic hallmark [40] because they are in contrast to the small to mediumsized megakaryocytes found in SP $[37,43]$. The finding 
of the specific histological pattern of a left-shifted (immature) erythroid and granulocytic proliferation associated with a megakaryopoiesis displaying a striking variety of cell sizes is in contrast to the uniformly large to giant size of the megakaryocytes in ET, which are usually not accompanied by significant proliferation in the other cell lineages $[28,29,46]$. Discriminate analysis of standardized BM features [35] in erythrocytosis reveals that in addition to the peculiar appearance of the megakaryocytes, certain constituents of the stroma compartment also enable a clear-cut distinction between PV and SP. Iron-laden macrophages are rarely observable in PV, and are found in about $6 \%$ of patients, which is opposed to the frequent occurrence of this phenomenon in SP [37, 43]. An increase in reticulin fibers is never encountered in SP $[37,43]$. Usually, SP shows an inflammatory reaction with prominent perivascular plasma cells, many scattered eosinophils and small accumulations of cell debris ingested by macrophages. The latter features are most prominent in so-called smoker's polycythemia associated with recurrent bronchopulmonary infections $[37,43,47]$.

Advanced and terminal stages of PV (spent phase, PPMM) are characterized by an increasing proliferation of (left-shifted) neutrophil granulopoiesis associated with a reduction of nucleated erythroid precursors and a conspicuous growth of megakaryocytes that show maturation defects [45]. These abnormalities of maturation may create bizarre forms of megakaryopoiesis as signs of acceleration [40]. PPMM is associated with different degrees of reticulin and collagen fibrosis $[45,48]$ and in most cases not distinguishable by clinical (leukoerythroblastosis, teardrop erythrocytosis and splenomegaly) as well as by BM findings from advanced stages of CIMF $[29,49]$. Even the assessment of the JAK2 mutation status reveals no unequivocal diagnostic specificity in this context, since a large number of advanced cases with CIMF carry this mutation [26].

\section{Essential Thrombocythemia}

A scrutinized review of the PVSG criteria for ET [2-5] reveals that differentiation is explicitly focused on the exclusion of chronic myeloid leukemia and manifest (polycythemic) stages of PV, but not on early-stage CIMF without myeloid metaplasia (MMM). For this reason, patients which show some degree of collagen fibrosis $(<1 / 3$ biopsy area) in the BM, but no marked splenomegaly or a leukoerythroblastic blood picture are included [3-5]. It has been demonstrated that prefibrotic and early stages of CIMF with their frequently associated thrombocythemia are not excluded $[28,31,33,34,46,50-54]$ as well as prodromal stages of PV $[37,40,55]$ with a red blood cell mass or hemoglobin level below the required limit [39], i.e. socalled latent PV or idiopathic (pure) erythrocytosis [56]. As a consequence, according to the WHO classification, BM histopathology was assumed to be an essential tool for a more accurate definition of positive diagnostic guidelines $[28,29,57]$. When applying these criteria, significant differences compared to the gold standard of the PVSG are obvious $[28,29,57]$. The latter may exert a relevant impact on the definition of risk groups evolving into myelofibrosis and blastic crisis $[30,58]$ and therefore may have also an effect on prospective treatment strategies.

A wealth of data has accumulated concerning the role of BM pathology in the differential diagnosis of thrombocythemia with the aim to define more clearly histological patterns that characterize (true) ET $[32,46]$. In contrast to prefibrotic CIMF with accompanying thrombocythemia, in (true) ET neither a relevant increase in cellularity nor a significant left-shifted neutrophil granulopoiesis is observable $[28,29,38,57]$. The most conspicuous differences are related to megakaryopoiesis, because in true ET gross disturbances of histotopography (dense clustering) are unusual, but a more or less random distribution of megakaryocytes within the BM is prevalent [28, $33,38]$. In (true) ET, there is a predominance of large to giant mature megakaryocytes with extensively lobulated (staghorn-like) nuclei $[28,33,38,46]$ surrounded by a correspondingly mature cytoplasm (fig. 2a, c). These features are clearly distinguishable from the abnormally hypolobulated (cloud-like) and hyperchromatic nuclei of megakaryocytes in prefibrotic-early CIMF (fig. $2 \mathrm{~b}, \mathrm{~d}$ ) with their striking maturation defects that result in a marked anomaly of nuclear-cytoplasmic maturation [38], i.e. megakaryocyte dysplasia. Finally, at presentation, there is no substantial increase in reticulin observable in (true) ET [59], a finding that is in significant contrast to the description of fibrosis in the criteria of the PVSG [3]. Using standardized features of BM assessment that include histopathology [35], a definitive differentiation between (true) ET and those entities mimicking this disorder may be easily achieved (fig. 1). This distinction of (true) ET according to the WHO classification [60] implies significant consequences regarding complications like myelofibrosis, therapeutic strategies and outcome $[28,29,58,61]$, because depending on risk status only a fraction of those cases diagnosed by the PVSG cri- 
Fig. 2. Megakaryopoiesis in (true) ET (a, c) and early CMPDs (b, d). a Abnormal dislocation of megakaryocytes towards the endosteal (paratrabecular) border and loose clustering. b Dense clusters in early CIMF. c ET reveals giant megakaryocytes with hyperlobulated nuclei without maturation defects. d Conspicuous abnormalities of clustered megakaryocytes in early CIMF with hyperchromatic and hypolobulated nuclei.
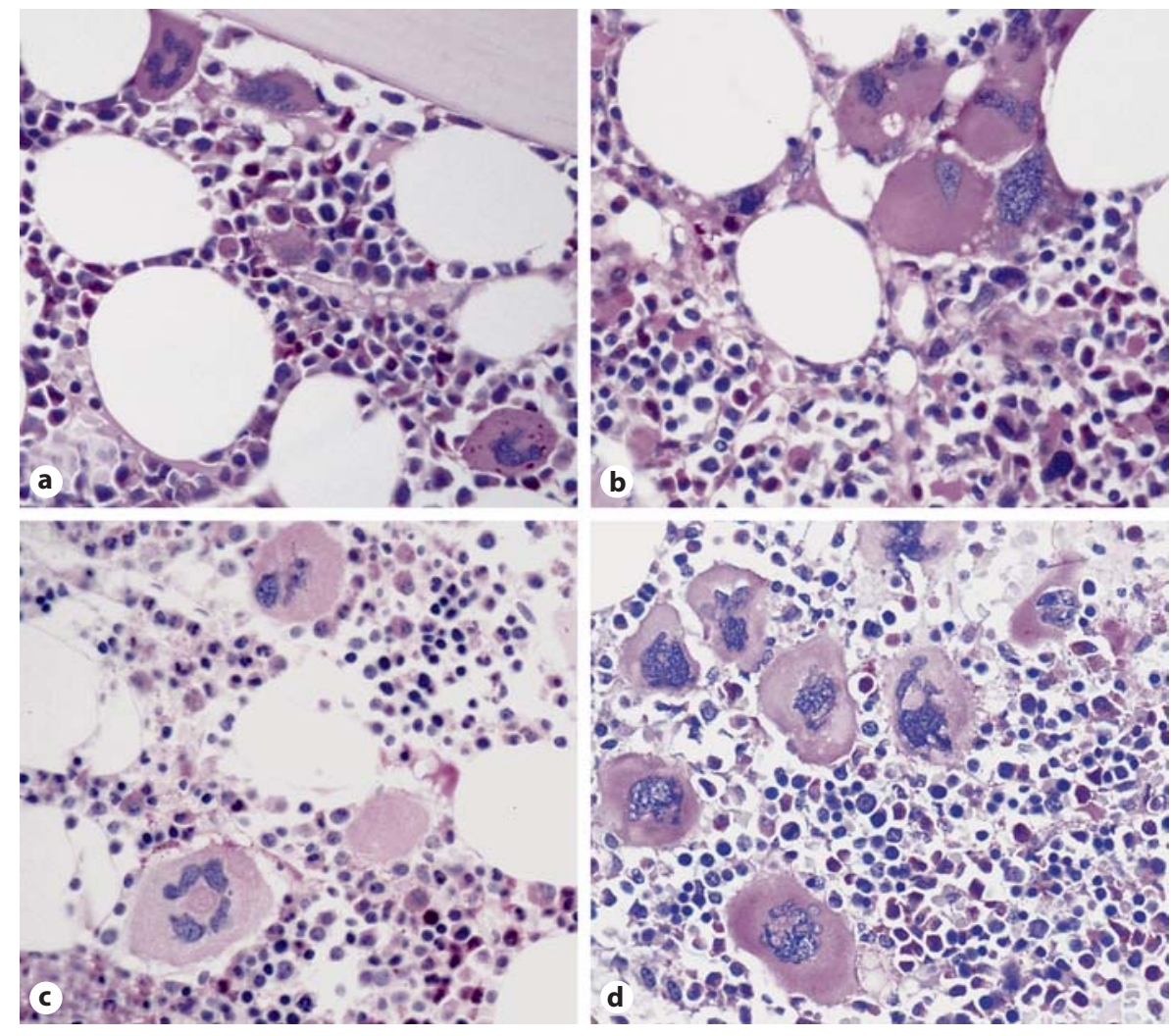

teria, ranging from 30 to $50 \%$, may be regarded as (true) ET [57].

In this context, the conflicting data regarding myelofibrotic transformation in ET and associated risk stratifications should be reconsidered [10, 30, 48, 62], since in a number of previous studies incidence of myelofibrosis with myeloid metaplasia (MMM) was reported to range from 5 to $24 \%$ [30, 63, 64]. By definition, myelofibrosis implicates an overall increase in $\mathrm{BM}$ reticulin or collagen fibers [36]. Accordingly, progression of myelofibrosis has to be assessed explicitly by sequential biopsy specimens during follow-up examinations and an appropriate semiquantitative grading system [36]. Contrasting this morphological approach, clinical diagnosis of myelofibrosis is only based on signs and symptoms of MMM indicative for clonally transformed extramedullary hematopoiesis, i.e. increase in anemia and splenomegaly, as well as occurrence of leukoerythroblastosis [30]. The significant difference between these two definitions has to be kept in mind, because early stages of myelofibrosis with only borderline to mild increase in reticulin may not be recognized by clinical features alone and thus progression of myelofibrosis is significantly underestimated [59]. In the recently published UK-PT1 study, MMM occurred after an observation time of 39 months dependent on therapy in 21 of 809 patients (overall incidence of $2.6 \%$ ) at higher risk for vascular events [10]. However, in this trial a critical issue is the assessment and diagnosis of myelofibrosis $[65,66]$, in particular since repeatedly performed BM biopsies were available in only 12 of the 21 cases [10], and thus myelofibrosis was assessed mainly by clinical diagnosis following the modified Italian criteria consistent with MMM $[67,68]$. In another large, but retrospective cohort of 195 ET patients, evolution into myelofibrosis, i.e. MMM, occurred in 13 cases (6.7\%) after a median of 8 years from diagnosis [30]. A significant shortcoming of this study is the lack of clear-cut data concerning the systematic evaluation of BM biopsies at onset, and it seems likely that sequential trephines were only performed when patients already developed signs and symptoms of MMM [30]. For this reason, neither early stages of (reticulin) fiber increase nor precursor stages of CIMF were recognized [34, 38]. In contrast to these data, in (true) ET according to the WHO classification [60] progression into myelofibrosis is generally not seen $[28,29,34,48,59$, $66,69]$. 


\section{Chronic Idiopathic Myelofibrosis}

CIMF initially presents with a hypercellular BM consistent with a prominent granulocytic and megakaryocytic myeloproliferation but no increase in reticulin [51, 53]. The predominance of the neutrophil (often left-shifted) and megakaryocytic lineages, with a concomitant reduction and maturation arrest of the nucleated erythroid precursors [70] was previously termed chronic megakaryocytic-granulocytic myelosis [71-74]. Most conspicuous, however, is the megakaryopoiesis characterized not only by a disturbance of BM histotopography (loose to dense clustering and translocation to the endosteal borders), but also by striking abnormalities of maturation $[29,34,35,38]$. Significant anomalies of megakaryocytes (fig. 2b, d) include variations in size (small to giant forms), and, in particular, an aberration of the nuclear cytoplasmic ratio leading to bulbous and hyperchromatic cloudlike nuclei [35]. Furthermore, many naked (bare) megakaryocytic nuclei are detectable $[27,75]$. Overall, the megakaryocytes in CIMF regularly are marked by a more atypical (dysplastic) appearance than in any other subtype of the CMPDs significantly contrasting those seen in (true) ET [28, 29, 38, 72, 76, 77]. Although progression of CIMF is unpredictable, increasing megakaryocytic maturation defects (dysplasia) are associated with a more rapid transition from the prefibrotic into overt fibrosclerotic stages, however, this transition is not dependent on the platelet count [58]. As has been elucidated in different studies, there is a more than $65 \%$ probability of progression from a prefibrotic-early stage to a full-blown CIMF or MMM conforming with the classical diagnostic criteria $[29,34,57]$. This disease progress is accompanied by relevant changes in clinical findings $[49,66,78]$. Patients that initially present with early-stage CIMF are prone to develop increasing anemia, splenomegaly and a leukoerythroblastic blood picture in the course of disease evolution merging finally into MMM [29, 49, 57, 66, 79]. Unfortunately, these prodromal stages of CIMF are not always taken into consideration $[28,57]$. Even in a recently published review that is primarily based on a molecular classification (i.e. JAK2 mutation status) of CMPDs [24], according to the (outdated) PVSG criteria [57], diagnosis of CIMF requires already overt collagen fibrosis of the BM [reticulin (fibrosis grade 3 or higher on 4-grade scale)]. For this reason, patients with CIMF and accompanying thrombocytosis will be misdiagnosed as ET or even labeled as unclassifiable [24].

In contrast to the prefibrotic-initial stages of CIMF (CIMF-0), the more advanced and fibro-osteosclerotic lesions of disease (CIMF-3) conforming with MMM are characterized by coarse bundles of collagen fibers in the BM $[29,34]$. There is usually an optional plaque-to-buddlike osteosclerosis (endophytic bone formation) detectable and areas of patchy hematopoiesis, revealing progressive hypoplasia [80]. Comparable with the initial stages, atypical megakaryocytes are again a most prominent feature including naked (denuded, condensed) nuclei and dilated marrow sinuses containing groupings of intraluminal hematopoiesis, especially megakaryocytes $[29,66]$. It is noteworthy that even without prior cytoreductive therapy mild to moderately expressed myelodysplastic changes may occur in the natural course of the disease process, occasionally indicating an insidious transition into an acceleration and terminal blastic crisis $[78,80]$. The differential diagnosis in such cases may include MDS with fibrosis, MDS/CMPD, or even acute panmyelosis with fibrosis. These latter disorders usually lack the typical morphologic features and the marked hepatosplenomegaly that characterize CIMF [81]. In this context it should be emphasized that maturation defects of the hematopoiesis may present a major diagnostic pitfall, since myelodysplastic changes are frequently observed following therapy and may simulate MDS or a socalled overlapping-transitional MDS/CMPD disorder [82]. In these cases it is absolutely mandatory to restrict the diagnosis of a MDS/CMPD to initial blood and BM examinations at first presentation and any therapy should be explicitly excluded $[29,66]$. Furthermore, it is important that in BM specimens maturation defects should be recognized in at least two lineages [82], especially erythropoiesis and megakaryocytes (atypical micromegakaryocytes, abnormal nuclear lobulation, compact nuclei) [83]. Finally, although in the past decade many groups were engaged in the study of risk stratification and prognosis of CIMF patients, a comparison of these data reveals an extreme heterogeneity $[84,85]$. This result may be significantly influenced by including patients with PPMM into the corresponding calculations and the failure to recognize the prefibrotic and early stages of this disorder $[58,85]$. On the other hand, it is reasonable to assume that survival may be related to stages in which CIMF is diagnosed $[29,34,77]$. In univariate analysis, the prodromal phases show a more favorable survival in comparison with more advanced stages (MMM). However, in multivariate calculations, evolution of BM fibrosis displayed no significant influence on survival [8486]. 


\begin{tabular}{|c|c|c|c|}
\hline $\begin{array}{l}\text { Morphological features } \\
\text { in CMPDs }\end{array}$ & PV & ET & early CIMF \\
\hline Increased cellularity & $\oplus \oplus \oplus$ & $\varnothing$ & $\oplus \oplus \oplus$ \\
\hline \multicolumn{4}{|l|}{ Megakaryopoiesis } \\
\hline maturation defects & $\varnothing$ & $\varnothing$ & $\oplus$ \\
\hline \multicolumn{4}{|l|}{ nuclear lobulation } \\
\hline naked nuclei & $\oplus$ & $\oplus$ & $\oplus \oplus \oplus$ \\
\hline small forms & $\oplus \oplus$ & $\varnothing \varnothing \varnothing$ & $\oplus \oplus$ \\
\hline giant forms & $\varnothing \varnothing \varnothing$ & $\oplus \oplus$ & $\oplus \oplus$ \\
\hline bulbous nuclei & $\varnothing \varnothing \varnothing$ & $\varnothing$ & $\oplus \oplus$ \\
\hline histotopography & $\begin{array}{l}\text { dispersed or } \\
\text { loose clusters }\end{array}$ & $\begin{array}{l}\text { dispersed or } \\
\text { loose clusters }\end{array}$ & dense clusters \\
\hline \multicolumn{4}{|l|}{ Erythropoiesis } \\
\hline quantity & $\oplus \oplus \oplus$ & $\varnothing \varnothing$ & $\varnothing \varnothing$ \\
\hline left shifting & $\oplus \oplus \oplus$ & $\varnothing \varnothing$ & $\varnothing \varnothing \varnothing$ \\
\hline \multicolumn{4}{|l|}{ Granulopoiesis } \\
\hline quantity & $\oplus \oplus \oplus$ & $\varnothing \varnothing$ & $\oplus \oplus$ \\
\hline left shifting & $\oplus \oplus$ & $\varnothing \varnothing \varnothing$ & $\oplus$ \\
\hline Myelofibrosis & $\varnothing^{*}$ & $\varnothing$ & $\varnothing \Rightarrow \oplus$ \\
\hline
\end{tabular}

Incidence of specific features: $\varnothing$ absent, $\oplus$ present

Fig. 3. Diagnostic flowchart for the differentiation of early CMPDs according to bone marrow morphology. ET = Essential thrombocythemia; $\mathrm{PV}=$ polycythemia vera; $\mathrm{CIMF}=$ chronic idiopathic myelofibrosis. ${ }^{*}$ In $10 \%$ to $20 \%$ of cases reticulin fibrosis at time of diagnosis.

\section{Conclusion}

The various subtypes of CMPDs are characterized by specific patterns of histopathology. When considered in the context of clinical findings, the histological features not only enable differential diagnosis (fig. 3), but also provide valuable information that can identify various risk groups, predict prognosis, and assess therapeutic efficacy. Histopathology is especially crucial to distinguish between CMPDs in which the clinical and laboratory features overlap, but the prognosis and therapeutic implications are significantly different. For example, prefibrotic CIMF is frequently associated with thrombocythemia and thus, easily misdiagnosed as ET, from which it differs markedly in terms of development of fibrosis, blast transformation and survival. Yet the histopathology of these two diseases is considerably different at onset and usually permits an accurate diagnosis. It is estimated that the majority of patients entered into clinical studies on ET, actually present early-stage CIMF with marked thrombocythemia (false ET). Similarly, the prodromal phase of $\mathrm{PV}$, which may also mimic ET, cannot be recognized by conventional criteria, but has a characteristic histopathology pattern. Of course, the dynamics of the disease process must always be taken into account when following individual patients, particularly in PV and CIMF, and follow-up studies with repeated BM biopsy specimens readily allow monitoring of disease progression.

\section{References}

1 Dickstein JI, Vardiman JW: Hematopathologic findings in the myeloproliferative disorders. Semin Oncol 1995;22:355-373.

2 Kutti J, Wadenvik H: Diagnostic and differential criteria of essential thrombocythemia and reactive thrombocytosis. Leuk Lymphoma 1996;22(suppl 1):41-45.

3 Murphy S, Peterson P, Iland H, Laszlo J: Experience of the Polycythemia Vera Study Group with essential thrombocythemia: a final report on diagnostic criteria, survival, and leukemic transition by treatment. Semin Hematol 1997;34:29-39.

4 Murphy S: Diagnostic criteria and prognosis in polycythemia vera and essential thrombocythemia. Semin Hematol 1999;36:9-13.

5 Pearson TC: Diagnosis and classification of erythrocytoses and thrombocytoses. Baillieres Clin Haematol 1998;11:695-720.
6 Finazzi G, Barbui T: Treatment of essential thrombocythemia with special emphasis on leukemogenic risk. Ann Hematol 1999;78: 389-392.

7 Radaelli F, Mazza R, Curioni E, Ciani A, Pomati M, Maiolo AT: Acute megakaryocytic leukemia in essential thrombocythemia: an unusual evolution? Eur J Haematol 2002;69: 108-111.

8 Barbui T, Barosi G, Grossi A, Gugliotta L, Liberato LN, Marchetti M, Mazzucconi MG, Rodeghiero F, Tura S: Practice guidelines for the therapy of essential thrombocythemia. A statement from the Italian Society of Hematology, the Italian Society of Experimental Hematology and the Italian Group for Bone Marrow Transplantation. Haematologica 2004;89:215-232.
9 Cortelazzo S, Finazzi G, Ruggeri M, Vestri O, Galli M, Rodeghiero F, Barbui T: Hydroxyurea for patients with essential thrombocythemia and a high risk of thrombosis. N Engl J Med 1995;332:1132-1136.

10 Harrison CN, Campbell PJ, Buck G, Wheatley K, East CL, Bareford D, Wilkins BS, van der Walt JD, Reilly JT, Grigg AP, Revell P, Woodcock BE, Green AR: Hydroxyurea compared with anagrelide in high-risk essential thrombocythemia. N Engl J Med 2005;353:33-45.

11 Harrison CN, Green AR: Essential thrombocythemia. Hematol Oncol Clin North Am 2003;17:1175-1190.

12 Finazzi G, Harrison C: Essential thrombocythemia. Semin Hematol 2005;42:230238 
13 James C, Ugo V, Le Couedic JP, Staerk J, Delhommeau F, Lacout C, Garcon L, Raslova H, Berger R, Bennaceur-Griscelli A, Villeval JL, Constantinescu SN, CasadevallN, Vainchenker W: A unique clonal JAK2 mutation leading to constitutive signalling causes polycythaemia vera. Nature 2005;434:1144-1148.

14 Baxter EJ, Scott LM, Campbell PJ, East C, Fourouclas N, Swanton S, Vassiliou GS, Bench AJ, Boyd EM, Curtin N, Scott MA, Erber WN, Green AR: Acquired mutation of the tyrosine kinase JAK2 in human myeloproliferative disorders. Lancet 2005;365: 1054-1061.

15 Kralovics R, Passamonti F, Buser AS, Teo SS, Tiedt R, Passweg JR, Tichelli A, Cazzola M, Skoda RC: A gain-of-function mutation of JAK2 in myeloproliferative disorders. $\mathrm{N}$ Engl J Med 2005;352:1779-1790.

16 Levine RL, Wadleigh M, Cools J, Ebert BL, Wernig G, Huntly BJ, Boggon TJ, Wlodarska I, Clark JJ, Moore S, Adelsperger J, Koo S, Lee JC, Gabriel S, Mercher T, D'Andrea A, Frohling S, Dohner K, Marynen P, Vandenberghe P, Mesa RA, Tefferi A, Griffin JD, Eck MJ, Sellers WR, Meyerson M, Golub TR, Lee SJ, Gilliland DG: Activating mutation in the tyrosine kinase JAK2 in polycythemia vera, essential thrombocythemia, and myeloid metaplasia with myelofibrosis. Cancer Cell 2005;7:387-397.

17 Jones AV, Kreil S, Zoi K, Waghorn K, Curtis C, Zhang L, Score J, Seear R, Chase AJ, Grand FH, White H, Zoi C, Loukopoulos D, Terpos E, Vervessou EC, Schultheis B, Emig M, Ernst T, Lengfelder E, Hehlmann R, Hochhaus A, Oscier D, Silver RT, Reiter A, Cross NC: Widespread occurrence of the JAK2 V617F mutation in chronic myeloproliferative disorders. Blood 2005;106:2162-2168.

18 Zhao R, Xing S, Li Z, Fu X, Li Q, Krantz SB, Zhao ZJ: Identification of an acquired JAK2 mutation in polycythemia vera. J Biol Chem 2005;280:22788-22792.

19 Goerttler PS, Steimle C, Marz E, Johansson PL, Andreasson B, Griesshammer $\mathrm{M}$, Gisslinger H, Heimpel H, Pahl HL: The Jak2V617F mutation, PRV-1 overexpression, and erythroid colony formation define a similar cohort of MPD patients. Blood 2005; 106:2862-2864.

20 Wolanskyj AP, Lasho TL, Schwager SM, McClure RF, Wadleigh M, Lee SJ, Gilliland DG, Tefferi A: JAK2 mutation in essential thrombocythaemia: clinical associations and longterm prognostic relevance. Br J Haematol 2005;131:208-213.

21 Goldman JM: A unifying mutation in chronic myeloproliferative disorders. N Engl J Med 2005;352:1744-1746

22 Kaushansky K: On the molecular origins of the chronic myeloproliferative disorders: it all makes sense. Blood 2005;105:4187-4190.

23 Tefferi A, Gilliland DG: JAK2 in myeloproliferative disorders is not just another kinase. Cell Cycle 2005;4:1053-1056.
24 Campbell PJ, Green AR: The myeloproliferative disorders. N Engl J Med 2006;355:24522466.

25 Antonioli E, Guglielmelli P, Pancrazzi A, Bogani C, Verrucci M, Ponziani V, Longo G, Bosi A, Vannucchi AM: Clinical implications of the JAK2 V617F mutation in essential thrombocythemia. Leukemia 2005;19: 1847-1849.

26 Bock O, Neuse J, Hussein K, Brakensiek K, Buesche G, Buhr T, Wiese B, Kreipe H: Aberrant collagenase expression in chronic idiopathic myelofibrosis is related to the stage of disease but not to the JAK2 mutation status. Am J Pathol 2006;169:471-481.

27 Vardiman JW, Pierre R, Thiele J, Imbert M: Chronic myeloproliferative disorders; in Jaffe ES, Harris NL, Stein H, Vardiman JW (eds): WHO Classification of Tumours: Tumours of Haematopoietic and Lymphoid Tissues. Lyon, IARC Press, 2001, pp 16-59.

28 Thiele J, Kvasnicka HM: Clinicopathological criteria for differential diagnosis of thrombocythemias in various myeloproliferative disorders. Semin Thromb Hemost 2006;32: 219-230.

29 Thiele J, Kvasnicka HM, Vardiman J: Bone marrow histopathology in the diagnosis of chronic myeloproliferative disorders: a forgotten pearl. Best Pract Res Clin Haematol 2006;19:413-437.

30 Cervantes F, Alvarez-Larran A, Talarn C, Gomez M, Montserrat E: Myelofibrosis with myeloid metaplasia following essential thrombocythaemia: actuarial probability, presenting characteristics and evolution in a series of 195 patients. Br J Haematol 2002; 118:786-790.

31 Gianelli U, Vener C, Raviele PR, Moro A, Savi F, Annaloro C, Somalvico F, Radaelli F, Franco V, Deliliers GL: Essential thrombocythemia or chronic idiopathic myelofibrosis? A single-center study based on hematopoietic bone marrow histology. Leuk Lymphoma 2006;47:1774-1781.

32 Thiele J, Kvasnicka HM, Fischer R: Histochemistry and morphometry on bone marrow biopsies in chronic myeloproliferative disorders - aids to diagnosis and classification. Ann Hematol 1999;78:495-506.

33 Florena AM, Tripodo C, Iannitto E, Porcasi $\mathrm{R}$, Ingrao S, Franco V: Value of bone marrow biopsy in the diagnosis of essential thrombocythemia. Haematologica 2004;89:911-919.

34 Thiele J, Kvasnicka HM, Orazi A: Bone marrow histopathology in myeloproliferative disorders - current diagnostic approach. Semin Hematol 2005;42:184-195.

35 Thiele J, Kvasnicka HM, Diehl V: Standardization of bone marrow features - does it work in hematopathology for histological discrimination of different disease patterns? Histol Histopathol 2005;20:633-644.
36 Thiele J, Kvasnicka HM, Facchetti F, Franco V, van der Walt J, Orazi A: European consensus on grading bone marrow fibrosis and assessment of cellularity. Haematologica 2005. 90:1128-1132.

37 Thiele J, Kvasnicka HM, Zankovich R, Diehl $\mathrm{V}$ : The value of bone marrow histology in differentiating between early stage polycythemia vera and secondary (reactive) polycythemias. Haematologica 2001;86:368374.

38 Thiele J, Kvasnicka HM: Diagnostic differentiation of essential thrombocythaemia from thrombocythaemias associated with chronic idiopathic myelofibrosis by discriminate analysis of bone marrow features - a clinicopathological study on 272 patients. Histol Histopathol 2003;18:93-102.

39 Spivak JL: Polycythemia vera: myths, mechanisms, and management. Blood 2002;100: 4272-4290.

40 Thiele J, Kvasnicka HM: Diagnostic impact of bone marrow histopathology in polycythemia vera. Histol Histopathol 2005;20: 317-328.

41 Pierre R, Imbert M, Thiele J, Vardiman JW, Brunning RD, Flandrin G: Polycythaemia vera; in Jaffe ES, Harris NL, Stein H, Vardiman JW (eds): WHO Classification of Tumours: Tumours of Haematopoietic and Lymphoid Tissues. Lyon, IARC Press, 2001, pp 32-38.

42 Tefferi A: Current management of polycythemia vera. Leuk Lymphoma 2002;43:1-7.

43 Thiele J, Kvasnicka HM, Muehlhausen K, Walter S, Zankovich R, Diehl V: Polycythemia rubra vera versus secondary polycythemias. A clinicopathological evaluation of distinctive features in 199 patients. Pathol Res Pract 2001;197:77-84.

44 Ellis JT, Silver RT, Coleman M, Geller SA: The bone marrow in polycythemia vera. Semin Hematol 1975;12:433-444.

45 Ellis JT, Peterson P, Geller SA, Rappaport H: Studies of the bone marrow in polycythemia vera and the evolution of myelofibrosis and second hematologic malignancies. Semin Hematol 1986;23:144-155.

46 Thiele J, Kvasnicka HM, Zankovich R, Diehl $\mathrm{V}$ : Relevance of bone marrow features in the differential diagnosis between essential thrombocythemia and early stage idiopathic myelofibrosis. Haematologica 2000;85: 1126-1134.

47 Michiels JJ, Thiele J: Clinical and pathological criteria for the diagnosis of essential thrombocythemia, polycythemia vera, and idiopathic myelofibrosis (agnogenic myeloid metaplasia). Int J Hematol 2002;76:133-145.

48 Kreft A, Buche G, Ghalibafian M, Buhr T, Fischer T, Kirkpatrick CJ: The incidence of myelofibrosis in essential thrombocythaemia, polycythaemia vera and chronic idiopathic myelofibrosis: a retrospective evaluation of sequential bone marrow biopsies. Acta Haematol 2005;113:137-143. 
49 Thiele J, Kvasnicka HM: Myelofibrosis in chronic myeloproliferative disorders - dynamics and clinical impact. Histol Histopathol 2006;21:1367-1378.

50 Thiele J, Kvasnicka HM, Werden C, Zankovich R, Diehl V, Fischer R: Idiopathic primary osteo-myelofibrosis: a clinico-pathological study on 208 patients with special emphasis on evolution of disease features, differentiation from essential thrombocythemia and variables of prognostic impact. Leuk Lymphoma 1996;22:303-317.

51 Thiele J, Kvasnicka HM, Boeltken B, Zankovich R, Diehl V, Fischer R: Initial (prefibrotic) stages of idiopathic (primary) myelofibrosis - a clinicopathological study. Leukemia 1999;13:1741-1748.

52 Thiele J, Kvasnicka HM, Diehl V, Fischer R, Michiels J: Clinicopathological diagnosis and differential criteria of thrombocythemias in various myeloproliferative disorders by histopathology, histochemistry and immunostaining from bone marrow biopsies. Leuk Lymphoma 1999;33:207-218.

53 Thiele J, Kvasnicka HM: Prefibrotic chronic idiopathic myelofibrosis - a diagnostic enigma? Acta Haematol 2004;111:155-159.

54 Thiele J, Kvasnicka HM, Diehl V: Bone marrow features of diagnostic impact in erythrocytosis. Ann Hematol 2005;84:362-367.

55 Thiele J, Kvasnicka HM, Diehl V: Initial (latent) polycythemia vera with thrombocytosis mimicking essential thrombocythemia. Acta Haematol 2005;113:213-219.

56 Ruggeri M, Tosetto A, Frezzato M, Rodeghiero F: The rate of progression to polycythemia vera or essential thrombocythemia in patients with erythrocytosis or thrombocytosis. Ann Intern Med 2003;139:470-475.

57 Thiele J, Kvasnicka HM: Chronic myeloproliferative disorders with thrombocythemia: a comparative study of two classification systems (PVSG, WHO) on 839 patients. Ann Hematol 2003;82:148-152.

58 Kvasnicka HM, Thiele J: The impact of clinicopathological studies on staging and survival in essential thrombocythemia, chronic idiopathic myelofibrosis, and polycythemia rubra vera. Semin Thromb Hemost 2006;32: 362-371.

59 Thiele J, Kvasnicka HM, Schmitt-Graeff A, Zankovich R, Diehl V: Follow-up examinations including sequential bone marrow biopsies in essential thrombocythemia: a retrospective clinicopathological study of 120 patients. Am J Hematol 2002;70:283-291.

60 Imbert M, Pierre R, Thiele J, Vardiman JW, Brunning RD, Flandrin G: Essential thrombocythaemia; in Jaffe ES, Harris NL, Stein H, Vardiman JW (eds): WHO Classification of Tumours: Tumours of Haematopoietic and Lymphoid Tissues. Lyon, IARC Press, 2001, pp 39-41.

61 Thiele J, Kvasnicka HM, Fuchs N, Brunnbauer K, Volkwein N, Schmitt-Graeff A: Anagrelide-induced bone marrow changes during therapy of chronic myeloproliferative disorders with thrombocytosis - an immunohistochemical and morphometric study of sequential trephine biopsies. Haematologica 2003;88:1130-1138.

62 Harrison CN: Essential thrombocythaemia: challenges and evidence-based management. Br J Haematol 2005;130:153-165.

63 Fenaux P, Simon M, Caulier MT, Lai JL, Goudemand J, Bauters F: Clinical course of essential thrombocythemia in 147 cases. Cancer 1990;66:549-556.

64 Annaloro C, Lambertenghi Deliliers G, Oriani A, Pozzoli E, Lambertenghi Deliliers D, Radaelli F, Faccini P: Prognostic significance of bone marrow biopsy in essential thrombocythemia. Haematologica 1999;84: $17-21$.

65 Barbui T, Finazzi G: When and how to treat essential thrombocythemia. N Engl J Med 2005;353:85-86.

66 Thiele J, Kvasnicka HM: A critical reappraisal of the WHO classification of the chronic myeloproliferative disorders. Leuk Lymphoma 2006;47:381-396.

67 Barosi G: Myelofibrosis with myeloid metaplasia: diagnostic definition and prognostic classification for clinical studies and treatment guidelines. J Clin Oncol 1999;17:29542970.

68 Barosi G, Ambrosetti A, Finelli C, Grossi A Leoni P, Liberato NL, Petti MC, Pogliani E, Ricetti M, Rupoli S, Visani G, Tura S: The Italian Consensus Conference on diagnostic criteria for myelofibrosis with myeloid metaplasia. Br J Haematol 1999;104:730-737.

69 Buhr T, Georgii A, Schuppan O, Amor A, Kaloutsi V: Histologic findings in bone marrow biopsies of patients with thrombocythemic cell counts. Ann Hematol 1992;64:286291.

70 Thiele J, Windecker R, Kvasnicka HM, Titius BR, Zankovich R, Fischer R: Erythropoiesis in primary (idiopathic) osteomyelofibrosis: quantification, PCNA reactivity, and prognostic impact. Am J Hematol 1994;46:3642.

71 Buhr T, Georgii A, Choritz H: Myelofibrosis in chronic myeloproliferative disorders. Incidence among subtypes according to the Hannover Classification. Pathol Res Pract 1993;189:121-132.

72 Georgii A, Buesche G, Kreft A: The histopathology of chronic myeloproliferative diseases. Baillieres Clin Haematol 1998;11:721749.

73 Georgii A, Buhr T, Buesche G, Kreft A, Choritz $\mathrm{H}$ : Classification and staging of $\mathrm{Ph}$ negative myeloproliferative disorders by histopathology from bone marrow biopsies. Leuk Lymphoma 1996;22(suppl 1):15-29.

74 Georgii A, Vykoupil KF, Buhr T, Choritz H, Doehler U, Kaloutsi V, Werner M: Chronic myeloproliferative disorders in bone marrow biopsies. Pathol Res Pract 1990;186:327.
75 Thiele J, Imbert M, Pierre R, Vardiman JW, Brunning RD, Flandrin G: Chronic idiopathic myelofibrosis; in Jaffe ES, Harris NL, Stein H, Vardiman JW (eds): WHO Classification of Tumours: Tumours of Haematopoietic and Lymphoid Tissues. Lyon, IARC Press, 2001, pp 35-38.

76 Buhr T, Choritz H, Georgii A: The impact of megakaryocyte proliferation of the evolution of myelofibrosis. Histological follow-up study in 186 patients with chronic myeloid leukaemia. Virchows Arch A Pathol Anat Histopathol 1992;420:473-478.

77 Thiele J, Kvasnicka HM: Hematopathologic findings in chronic idiopathic myelofibrosis. Semin Oncol 2005;32:380-394.

78 Thiele J, Kvasnicka HM, Schmitt-Graeff A, Diehl V: Bone marrow histopathology following cytoreductive therapy in chronic idiopathic myelofibrosis. Histopathology 2003;43:470-479.

79 Buhr T, Buesche G, Choritz H, Langer F, Kreipe $\mathrm{H}$ : Evolution of myelofibrosis in chronic idiopathic myelofibrosis as evidenced in sequential bone marrow biopsy specimens. Am J Clin Pathol 2003;119:152158

80 Thiele J, Kvasnicka HM, Schmitt-Graeff A, Diehl V: Dynamics of fibrosis in chronic idiopathic (primary) myelofibrosis during therapy: a follow-up study on 309 patients. Leuk Lymphoma 2003;44:949-953.

81 Thiele J, Kvasnicka HM, Schmitt-Graeff A: Acute panmyelosis with myelofibrosis. Leuk Lymphoma 2004;45:681-687.

82 Bain BJ: The relationship between the myelodysplastic syndromes and the myeloproliferative disorders. Leuk Lymphoma 1999; 34:443-449.

83 Thiele J, Titius BR, Kopsidis C, Fischer R Atypical micromegakaryocytes, promegakaryoblasts and megakaryoblasts: a critical evaluation by immunohistochemistry, cytochemistry and morphometry of bone marrow trephines in chronic myeloid leukemia and myelodysplastic syndromes. Virchows Arch B Cell Pathol Incl Mol Pathol 1992;62: 275-282.

84 Kvasnicka HM, Thiele J, Regn C, Zankovich R, Diehl V, Fischer R: Prognostic impact of apoptosis and proliferation in idiopathic (primary) myelofibrosis. Ann Hematol 1999; 78:65-72.

85 Kvasnicka HM, Thiele J, Werden C, Zankovich R, Diehl V, Fischer R: Prognostic factors in idiopathic (primary) osteomyelofibrosis. Cancer 1997;80:708-719.

86 Strasser-Weippl K, Steurer M, Kees M, Augustin F, Tzankov A, Dirnhofer S, Fiegl M, Simonitsch-Klupp I, Zojer N, Gisslinger H, Ludwig H: Age and hemoglobin level emerge as most important clinical prognostic parameters in patients with osteomyelofibrosis: introduction of a simplified prognostic score. Leuk Lymphoma 2006;47:441-450. 